\title{
Morphology of GPS and DPS TEC over an equatorial station: validation of IRI and NeQuick 2 models
}

\author{
Olumide Olayinka Odeyemi ${ }^{1}$, Jacob Adeniyi ${ }^{2}$, Olushola Oladipo ${ }^{3}$, Olayinka Olawepo ${ }^{3}$, Isaac Adimula ${ }^{3}$, and \\ Elijah Oyeyemi ${ }^{1}$ \\ ${ }^{1}$ Department of Physics, University of Lagos, Lagos, Nigeria \\ ${ }^{2}$ Department of Physical Sciences, Landmark University, Omu-Aran, Nigeria \\ ${ }^{3}$ Department of Physics, University of Ilorin, Ilorin, Nigeria
}

Correspondence: Olumide Olayinka Odeyemi (oodeyemi@unilag.edu.ng)

Received: 2 June 2018 - Discussion started: 8 June 2018

Revised: 19 September 2018 - Accepted: 10 October 2018 - Published: 24 October 2018

\begin{abstract}
We investigated total electron content (TEC) at Ilorin $\left(8.50^{\circ} \mathrm{N} 4.65^{\circ} \mathrm{E}\right.$, dip lat. 2.95) for the year 2010, a year of low solar activity in 2010 with $R_{z}=$ 15.8. The investigation involved the use of TEC derived from GPS, estimated TEC from digisonde portable sounder data (DPS), and the International Reference Ionosphere (IRI) and NeQuick 2 (NeQ) models. During the sunrise period, we found that the rate of increase in DPS TEC, IRI TEC, and NeQ TEC was higher compared with GPS TEC. One reason for this can be attributed to an overestimation of plasmaspheric electron content (PEC) contribution in modeled TEC and DPS TEC. A correction factor around the sunrise, where our finding showed a significant percentage deviation between the modeled TEC and GPS TEC, will correct the differences. Our finding revealed that during the daytime when PEC contribution is known to be absent or insignificant, GPS TEC and DPS TEC in April, September, and December predict TEC very well. The lowest discrepancies were observed in May, June, and July (June solstice) between the observed values and all the model values at all hours. There is an overestimation in DPS TEC that could be due to extrapolation error while integrating from the peak electron density of F2 $(N m \mathrm{~F} 2)$ to around $\sim 1000 \mathrm{~km}$ in the Ne profile. The underestimation observed in NeQ TEC must have come from the inadequate representation of contribution from PEC on the topside of the NeQ model profile, whereas the exaggeration of PEC contribution in IRI TEC amounts to overestimation in GPS TEC. The excess bite-out observed in DPS TEC and modeled TEC indicates over-prediction of the fountain effect in these models. Therefore, the daytime bite-out observed
\end{abstract}

in these models requires a modifier that could moderate the perceived fountain effect morphology in the models accordingly. The daytime DPS TEC performs better than the daytime IRI TEC and NeQ TEC in all the months. However, the dusk period requires attention due to the highest percentage deviation recorded, especially for the models, in March, November, and December. Seasonally, we found that all the TECs maximize and minimize during the March equinox and June solstice, respectively. Therefore, GPS TEC and modeled TEC reveal the semiannual variations in TEC.

\section{Introduction}

Total electron content (TEC) is the total number of free electrons in a columnar of $1 \mathrm{~m}^{2}$ along the radio path from the satellite to the receiver on the Earth. TEC exhibits diurnal, seasonal, solar cycle, and geographical variations. Therefore, the physical and dynamical morphology of the TEC over a given location is of great importance in transionospheric communications during both quiet and disturbed geomagnetic conditions (Aravindan and Iyer, 1990; Akala et al., 2012; Olawepo et al., 2015; Tariku, 2015 and de Jesus et al., 2016). GPS TEC is quantified from the GPS orbiting satellites to the GPS receiver station on the Earth, with an approximate distance of $20200 \mathrm{~km}$ (Liu et al., 2006). Thus, a typical GPS TEC measurement incorporates the complete plasmaspheric electron content (PEC). The digisonde portable sounder (DPS) estimates the bottomside and topside TEC to obtain the total TEC from the electron density $\left(N_{\mathrm{e}}\right)$ profile. 
The topside DPS TEC is extrapolated from the peak electron density of the $\mathrm{F} 2$ region $(N m \mathrm{~F} 2)$ to around $\sim 1000 \mathrm{~km}$; thus, the significant PEC contribution from the higher altitudes is omitted from DPS TEC measurement (Reinisch and Huang, 2001; Belehaki et al., 2004 and Zhang et al., 2006).

The International Reference Ionosphere (IRI) model depends on worldwide data from various measurements (Bilitza, 1986, 2000; Bilitza and Rawer, 1998). The IRI model provides reliable ionospheric densities, composition, temperatures, and composition in the ionospheric altitude range (Radicella et al., 1998; Bilitza, 2000 and Coisson et al., 2009). The latest version of the IRI model can be found at all time on the web (https://ccmc.gsfc.nasa.gov/modelweb/ models/iri2016_vitmo.php; last access: 22 October 2018) with improvements on earlier versions of the model. The NeQuick 2 (NeQ) model makes use of the position, time and solar flux or sunspot number over a given location as variables in the NeQ model code (Coisson et al., 2006; Bidaine and Warnant, 2011 and Andreeva and Lokota, 2013). The output of the NeQ program and corresponding TEC are given by the electron density along any ray path and numerical integration in space and time respectively.

The availability of ionospheric parameters for global ionospheric models is deficient over the African sector compared to the consistent input of the data from the Asian and American sectors. Therefore, the continuing investigations of the parameters over Africa are required to improve the global ionospheric model. For example, Bagiya et al. (2009) studied TEC around an equatorial, low-latitude region at Rajkot $\left(22.29^{\circ} \mathrm{N}, 70.74^{\circ} \mathrm{E}\right.$, dip $\left.14.03^{\circ} \mathrm{N}\right)$ during low solar activity, Olwendo et al. (2012) and Karia and Pathak (2011) investigated the TEC data at Kenyan and Surat (India), respectively. They all noticed a semiannual variation with minimum and maximum TEC in the June solstice and March equinox, respectively. Using the Faraday rotational technique, Olatunji (1967) investigated TEC variation over the equatorial latitude at Ibadan. He observed no daytime bite-out and seasonal anomaly over the region. Rastogi et al. (1975) observed the diurnal variation of TEC using Faraday rotation over the magnetic equator. They noticed that TEC at the topside was higher than TEC at the bottomside during the nighttime; however, during the daytime they observed a uniform distribution of the TEC, on the topside and the bottomside of $N_{\mathrm{e}}$ profile.

Regarding the DPS TEC measurement, Barbas et al. (2010) examined GPS TEC and DPS TEC at Tucuman $\left(26.69^{\circ} \mathrm{S}, 65.23^{\circ} \mathrm{W}\right)$ during different seasons. They inferred that the DPS TEC represented the GPS TEC with a minimal discrepancy in all seasons. Reinisch et al. (2004) investigated GPS TEC and DPS TEC in a mid-latitude and equatorial region. They observed that the variations in GPS TEC and DPS TEC appeared similar, but the daytime values of GPS TEC were higher than daytime DPS TEC. Zhang et al. (2004) studied the variations in DPS TEC and GPS TEC over Hainan and reported that the daytime DPS TEC and GPS
TEC were similar in value during the daytime, but during the dusk period, they observed a significant discrepancy between DPS TEC and GPS TEC. Belehaki et al. (2004) extracted the PEC from the GPS TEC at Athens $\left(38^{\circ} \mathrm{N}, 23.5^{\circ} \mathrm{E}\right)$ for over a year. They reported a maximum and minimum contribution of PEC in the morning and evening, respectively. Mosert et al. (2007), Jodogne et al. (2004) and McKinnell et al. (2007) concluded that approximated PEC from the GPS TEC and DPS TEC is possible in colocated GPS and DPS station. Adewale et al. (2012), Okoh et al. (2015), Jee et al. (2005), Kenpankho et al. (2013), Sulungu et al. (2018), and Migoya Orué et al. (2008) validated the IRI TEC with GPS TEC at different regions and found high discrepancies between the IRI TEC and GPS TEC when compared to different IRI-model options.

Cherniak and Zakharenkova (2016) validated the NeQ model. They established underestimation of the topside ionosphere above $\sim 500 \mathrm{~km}$ in the NeQ model, due to inaccurate representation of the topside $N_{\mathrm{e}}$ profile. Rabiu et al. (2014) validated the NeQ model using GPS TEC over the equatorial region of Africa. They reported that the upper boundary of the NeQ model, up to $20,000 \mathrm{~km}$, needed to be adjusted to accommodate the PEC TEC in the NeQ model. Leong et al. (2015) investigated TEC and the NeQ model. They found that the observed and NeQ TEC were similar in value during dusk periods, but the changed TEC revealed higher discrepancies postsunset. Yu et al. (2012) investigated the monthly average of NeQ TEC model over three stations in China (Changchun, Beijing, and Chongqing) during the quietest period (i.e. days with $A p \leq 4$ ). They revealed that NeQ correctly predicted GPS TEC. However, the NeQ TEC underestimated the GPS TEC during the dusk period. Rios et al. (2007) investigated the variations in DPS TEC and IRI TEC and found that DPS TEC was smaller compared to IRI TEC. McNamara (1985) observed discrepancies between DPS TEC and IRI TEC and found that the IRI underestimated the DPS TEC during the daytime. Obrou et al. (2008) compared the DPS TEC and IRI TEC at Korhogo during high and low solar activity. They found that the variations in DPS TEC and IRI TEC were similar in value during high solar activity (HSA) and low solar activity (LSA), but the performance of IRI TEC was better during HSA compared to LSA.

The current contributions of Africa to the improvement of ionospheric models (IRI and NeQuick) are not adequate compared with the continuous support received from Asia and South America. The insufficient instrumentation at the equatorial region of Africa has a considerable effect on this shortcoming. Therefore, the constant validation of IRI and models with the observed parameter is necessary for an improved ionospheric model. Furthermore, the investigation on DPS TEC has not been reported extensively for comparison purposes over the equatorial region of Africa. Therefore, this study investigates the linked morphologies between the variations in GPS TEC and DPS TEC as well as validations of IRI TEC and NeQ TEC models with the observed parame- 
ters. Our finding will inform the suitability of modeled TEC in place of GPS TEC. The result will also determine the appropriate model for the equatorial latitude in Africa. Thus, the deviations in TEC obtained from the combined relationship between GPS TEC, DPS TEC, IRI TEC, and NeQ TEC could be used to correct the discrepancy in the models.

\section{Methods of analysis of GPS and DPS data}

Data used for this study are those of the five quietest days of each month of the year 2010. The five quietest days are days (with $\mathrm{Ap} \leq 4$ ) for which geomagnetic activities are quiet, which are obtained from the international quiet day (IQD) table available on the website of Geoscience Australia. The data are for Ilorin $\left(8.50^{\circ} \mathrm{N} 4.65^{\circ} \mathrm{E}\right.$, dip lat. 2.95) during the year 2010, a year of low solar activity. TEC data were obtained with a GPS receiver and DPS, both of which are located at the Ionospheric Laboratory of the University of Ilorin. The methods of data processing are described in the sections below.

\subsection{GPS TEC}

The slant TEC records from GPS have errors due to satellite differential delay (satellite bias (bS)), receiver differential delay (receiver bias (bR)), and receiver interchannel bias (bSR). This uncorrected slant GPS TEC, measured at every $1 \mathrm{~min}$ interval by the GPS receiver and derived from all the visible satellites at Ilorin station, are converted to vertical GPS TEC using the relation below in Eq. (1).

$$
\begin{aligned}
(\text { GPSTEC })_{\mathrm{V}}= & (\text { GPSTEC })_{\mathrm{S}} \\
& -[\mathrm{bS}+\mathrm{bR}+\mathrm{bSR}] / S(E),
\end{aligned}
$$

where (GPSTEC)S is the uncorrected slant GPS TEC measured by the receiver, $S(E)$ is the obliquity factor with zenith angle ( $z$ ) at the ionospheric pierce point (IPP), $E$ is the elevation angle of the satellites in degrees, and (GPSTEC) $\mathrm{V}$ is the vertical GPS TEC at the IPP. The equation two below provides $S(E)$ as

$S(E)=\frac{1}{\cos (z)}=\left[1-\left(\frac{R_{\mathrm{E}} \times \cos (E)}{R_{\mathrm{E}}+\mathrm{hS}}\right)^{2}\right]^{-\frac{1}{2}}$,

where $R_{\mathrm{E}}$ is the mean radius of the Earth measured in kilometer $(\mathrm{km})$, and $\mathrm{hS}$ is the height of the ionosphere from the surface of the Earth, which is approximately equal to $400 \mathrm{~km}$ according to Langley et al. (2002), Rama Rao et al. (2006a), and Mannucci et al. (1993). The data from the five quietest slant GPS TEC days for each month in the year 2010 were interpreted using Krishna software (Global positioning system total electron content analysis application user's manual, 2009, Institute for Scientific Research, Boston College, Chestnut Hill, Massachusetts, USA). This software reads raw data and corrects all source of errors mentioned above from
Global Navigation Satellite System (IGS) service code file. A minimum elevation angle of $20^{\circ}$ is used to avoid multipath errors. The estimated vertical GPS TEC data are a function of a two-sigma $(2 \sigma)$ iteration. This sigma is a measure of GPS point positioning accuracy. We converted the average $1 \mathrm{~min}$ VTEC data to hourly averages.

\subsection{DPS TEC}

Regarding the TEC from the DPS, the Standard Archive Output (SAO) files obtained from the DPS at the University of Ilorin were edited to remove magnetically disturbed days. Huang and Reinisch (2001) technique was used to compute the DPS TEC. The vertical DPS TEC computation by the technique is based on the application of the integration over the vertical electron density $\left[N_{\mathrm{e}}(h)\right]$ profile as shown in the Eq. (3) below.

$\mathrm{TEC}=\int_{0}^{h m \mathrm{~F} 2} N_{\mathrm{e}_{\mathrm{B}}}(\mathrm{d} h)+\int_{h m F 2}^{1000} N_{\mathrm{e}_{\mathrm{T}}}(\mathrm{d} h)$,

where $N_{\mathrm{e}_{\mathrm{B}}}$ and $N_{\mathrm{e}_{\mathrm{T}}}$ are the bottomside and topside $N_{\mathrm{e}}$ profiles, respectively. We computed the $N_{\mathrm{e}} \mathrm{B}$ from the recorded ionograms by using the inversion technique developed by Huang and Reinisch (1996a, b). The information above the peak of the F2 layer is absent from the record of the ionogram. Thus, the $N_{\mathrm{e}_{\mathrm{T}}}$ is measured by approximating the exponential functions with suitable scale height (Bent et al., 1972) with a lower estimated error of $5 \%$. The ionograms were manually scaled and inverted into electron density profiles using the NHPC software and later processed with the SAO explorer software based on the technique described above to obtain the TEC (Reinisch et al., 2005). We estimated an average of TEC for each hour over the selected days. Universal time (UT) is the time standard for the record of GPS and DPS data, but we converted UT to local time (LT) by adding $1 \mathrm{~h}$ to the corresponding UT. Nigeria is $1 \mathrm{~h}$ in advance of Greenwich mean time (GMT); thus, 01:00 UT is the same as 02:00 LT in Ilorin, Nigeria. The available months of the year were grouped into seasons in order to study the seasonal variation of TEC and the performances of some of the options in the IRI model. The four seasons are grouped as March equinox or MEQU (March and April), June solstice or JSOL (June and July), September equinox or SEQU (September and October) and December solstice or DSOL (November and December). The monthly median of the five quietest days were deduced and the average of the monthly median under a particular season as defined above to infer seasonal variations under GPS TEC, DPS TEC, IRI TEC, and NeQ TEC. The DPS in Ilorin was installed in March, 2010, as a result data were not available for the months of January to late March, 2010. Therefore, this study does not include the days for which DPS data were not available. 


\subsection{Validation of IRI - 2016 and NeQuick 2 models}

We correlated the observed TEC with modeled TEC in the IRI-2016 model. The website https://ccmc.gsfc.nasa.gov/ modelweb/models/iri2016_vitmo.php (last access: 22 October 2018) provides the modeled TEC values. We selected the upper boundary height $2000 \mathrm{~km}$ and the B0 table option for the bottomside shape parameter. The Eqs. $(4 a-c)$ represent the differences between GPS TEC and DPS TEC, GPS TEC and IRI TEC, and GPS TEC and NeQ TEC while Eqs. (5ac) below show the percentage change between GPS TEC and DPS TEC, GPS TEC and IRI TEC, and GPS TEC and NeQ TEC.

$$
\begin{aligned}
& \Delta_{\mathrm{DPS}-\mathrm{GPS}}=\mathrm{DPS}_{\mathrm{TEC}}-\mathrm{GPS}_{\mathrm{TEC}} \\
& \Delta_{\mathrm{IRI}-\mathrm{GPS}}=\mathrm{IRI}_{\mathrm{TEC}}-\mathrm{GPS}_{\mathrm{TEC}} \\
& \Delta_{\mathrm{NeQ}-\mathrm{GPS}}=\mathrm{NeQ}_{\mathrm{TEC}}-\mathrm{GPS}_{\mathrm{TEC}}
\end{aligned}
$$

$\%\left(\Delta_{\mathrm{DPS}-\mathrm{GPS}}\right)=\frac{\mathrm{DPS}_{\mathrm{TEC}}-\mathrm{GPS}_{\mathrm{TEC}}}{\mathrm{DPS}_{\mathrm{TEC}}} \times 100$

$\%\left(\Delta_{\mathrm{IRI}-\mathrm{GPS}}\right)=\frac{\mathrm{IRI}_{\mathrm{TEC}}-\mathrm{GPS}_{\mathrm{TEC}}}{\mathrm{IRI}_{\mathrm{TEC}}} \times 100$

$\%\left(\Delta_{\mathrm{NeQ}-\mathrm{GPS}}\right)=\frac{\mathrm{NeQ}_{\mathrm{TEC}}-\mathrm{GPS}_{\mathrm{TEC}}}{\mathrm{NeQ}_{\mathrm{TEC}}} \times 100$

$\Delta_{\text {DPS-GPS }}, \Delta_{\text {IRI-GPS }}$, and $\Delta_{\text {NeQ-GPS }}$ represent the difference between GPS TEC and DPS TEC, GPS TEC and IRI TEC, and GPS TEC and NeQ TEC, respectively, while $\%\left(\Delta_{\text {DPS-GPS }}\right), \%\left(\Delta_{\text {IRI-GPS }}\right)$, and $\%\left(\Delta_{\text {NeQ-GPS }}\right)$ represent the percentage deviation between GPS TEC and DPS TEC, GPS TEC and IRI TEC, and GPS TEC and NeQ TEC, respectively.

The Abdus Salam International Centre for Theoretical Physics (ICTP) in Trieste, Italy, in collaboration with the Institute for Geophysics, Astrophysics and Meteorology (IGAM) of the University of Graz, Austria, developed the web front end of NeQuick. This quick-run ionospheric electron density model developed at the Aeronomy and Radiopropagation Laboratory modeled TEC along any ground-to-satellite straight-line ray path. Therefore, we validated the NeQ obtained from https://t-ict4d.ictp.it/nequick2/ nequick-2-web-model (last access: 22 October 2018).

\section{Result}

\subsection{Monthly median variations in GPS and modeled TEC}

Figure 1a shows the simultaneous plots of hourly variations in the monthly median of TEC obtained from GPS,DPS, IRI, and NeQ TEC during the quiet period. The GPS TEC is denoted by a black line with the star symbol; the DPS TEC is denoted by a green line with the diamond symbol, IRI TEC is denoted by a red line with zero symbols, and finally, the $\mathrm{NeQ}$ TEC is denoted by a blue line with multiplication symbols. All the TEC plots are regulated by the same local time on the horizontal axis. The result reveals that the morphologies of GPS, DPS, and modeled TEC increase gradually from the sunrise period (07:00-09:00 LT) and reach the daytime maximum, mostly around (12:00-17:00 LT), and then later decay steadily until a minimum value around 06:00 LT. Therefore, our result suggests that the diurnal variations in the observed and modeled TEC capture the well known solar zenith angle dependence of TEC since both observed and modeled TEC characterize presunrise minimum, daytime maximum, daytime depression (modeled TEC), and postsunset decay. The lowest and highest presunrise minimum ranged from $\sim 0.66$ to $\sim 4.49$ TECU (DPS) while the lowest and highest daytime maximum found between $\sim 17.75 \mathrm{TECU}(\mathrm{NeQ})$ and $\sim 38.0 \mathrm{TECU}$ (DPS). The result shows noontime biteout in modeled TEC around 12:00 and 15:00 LT, except in GPS TEC where the bite-out was obscure apart from a slight shift in daytime maximum within 15:00 and 17:00 LT in all months. We observed two moderate peaks (prenoon and postnoon peaks) in DPS TEC and modeled TEC, indicating the bite-out effect on the modeled and DPS TEC signatures. We also found around the sunrise period, the model TEC rises faster than the GPS TEC, but IRI TEC rises faster compared to DPS TEC and NeQ TEC. Between 06:00 and 09:00 LT, the lowest and highest differences in the rises of IRI TEC compared to GPS TEC were $~ 5.0$ TECU (March) and $\sim 15.3$ TECU (November), respectively. The postnoontime decay was faster in DPS TEC compared to GPS TEC and modeled TEC in all months. Figure $1 \mathrm{~b}$ reveals the coincident seasonal variations in GPS, DPS, and modeled TEC during a quiet period of the (i) March equinox, (ii) June solstice, (iii) September equinox, and (iv) December solstice. The daytime maximum ranges are from $\sim 24.8 \mathrm{TECU}(\mathrm{NeQ})$ to $\sim 34 \mathrm{TECU}$ (DPS), $\sim 19.2 \mathrm{TECU}(\mathrm{NeQ})$ to $\sim 22.6 \mathrm{TECU}$ (DPS), $\sim 24.9$ TECU (NeQ) to $\sim 33.5 \mathrm{TECU}$ (DPS), and $\sim$ 24.55 TECU (NeQ) to $~ 31$ TECU (DPS), during the March equinox, June solstice, September equinox, and December solstice, respectively. We observed that the morphologies of GPS TEC and modeled TEC maximize and minimize during the March equinox and June solstice, thus indicating semiannual variation in observed and modeled TEC.

\subsection{Percentage deviation of DPS TEC, IRI TEC, and NeQ TEC}

Figures $2 \mathrm{a}, 3 \mathrm{a}$, and $4 \mathrm{a}$ are hourly variations in deviation in TEC $(\triangle T E C)$ between GPS-, DPS-, IRI- and NeQderived TEC whereas Figs. $2 b, 3 b$, and $4 b$ depict the mass plots of hourly variations in the percentage deviation (\% $\%$ TEC) during a quiet period from March to December. In Fig. 2a and $b$, the overestimation by DPS TEC as given by $\triangle$ TEC $_{\text {DPS-GPS }}$ is within the range of $\sim 5.13 \mathrm{TECU}$ (March) to $\sim 19.12 \mathrm{TECU}$ (July) around 
(a)
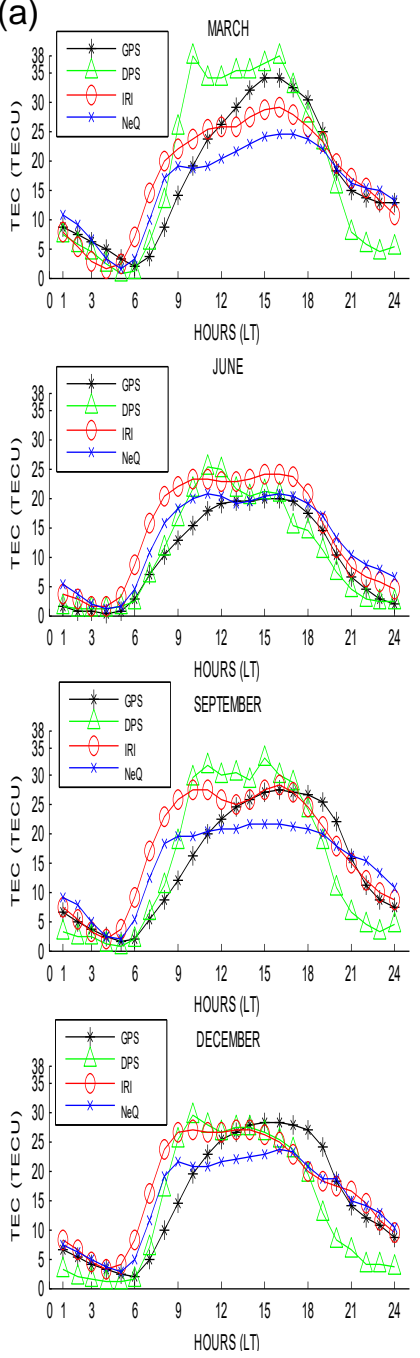
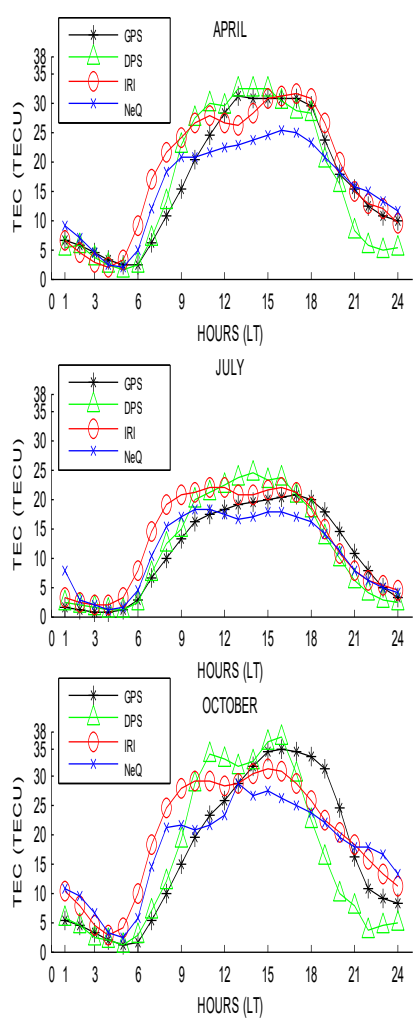
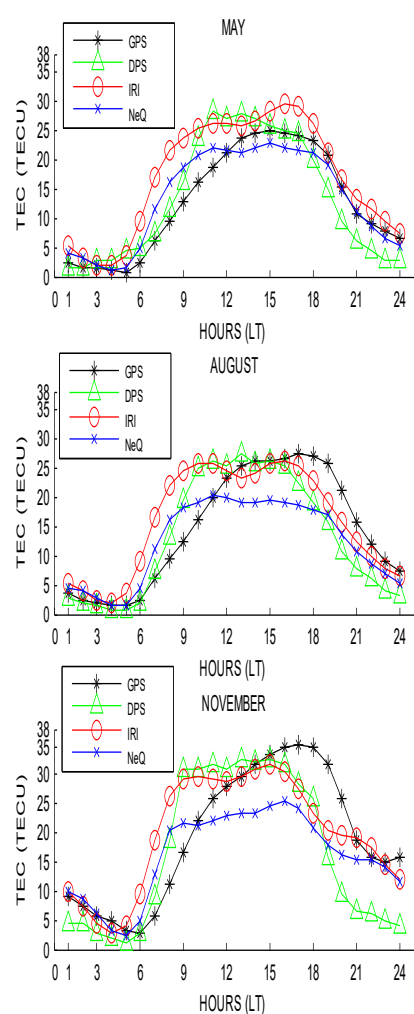

Figure 1.

07:00-16:00 LT while the underestimation $\triangle \mathrm{TEC}_{\mathrm{DPS}-\mathrm{GPS}}$ fluctuated between $\sim 3.2$ TECU (June) and $\sim 16.4$ TECU (November) around 17:00-24:00 LT. The overestimation and underestimation of $\% \Delta_{\text {IRI-GPS }}$ ranged from $\sim 2 \%$ to $\sim$ $49 \%$ and $\sim-1.36 \%$ to $\sim-306 \%$, respectively. From Figs. $3 \mathrm{a}$ and $\mathrm{b}$, the overestimation occurred regularly around 04:00-12:00 LT in all months. The overestimated and underestimated $\triangle \mathrm{TEC}_{\mathrm{IRI}-\mathrm{GPS}}$ were from $\sim 9.13 \mathrm{TECU}$ (July) to $\sim 15.3 \mathrm{TECU}$ (November) and $\sim 0.15 \mathrm{TECU}$ (October) to $\sim 0.95$ TECU (July), respectively. However, a few underestimations and overestimations of $\triangle \mathrm{TEC}_{\mathrm{IRI} I-\mathrm{GPS}}$ still occurred irregularly around 13:00-03:00 LT in all months. The result also shows that IRI TEC completely overestimated GPS TEC in May and June between 01:00 and 24:00 LT. The overestimation of $\% \Delta \mathrm{TEC}_{\text {IRI-GPS }}$ ranged between $\sim$ $0.1 \%$ and $\sim 86 \%$ in all months. In Figs. $4 \mathrm{a}$ and b, NeQ TEC overestimated GPS TEC at 01:00-11:00 and 20:0024:00 LT with $\triangle \mathrm{TEC}_{\mathrm{NeQ}-\mathrm{GPS}}$ ranging from $\sim 9.72$ (Septem- ber) to $\sim 0.01$ (April). We also found that NeQ TEC underestimated $\triangle \mathrm{TEC}_{\mathrm{NeQ}-\mathrm{GPS}}$ by between $\sim 0.11$ (May) and $\sim 9.72$ (November). The overestimations and underestimations of $\% \Delta \mathrm{TEC}_{\mathrm{NeQ}-\mathrm{GPS}}$ are from $\sim 0.02 \%$ to $\sim 81 \%$ and $\sim-0.3 \%$ to $\sim-75 \%$ respectively.

\subsection{Comparisons of the percentage deviations from GPS TEC}

In Figs. $2 b, 3 b$, and $4 b$, the percentage deviation between GPS and DPS TEC are more significant: greater than $100 \%$ in March-August, September, November, and December at 04:00-05:00 LT and around 22:00-24:00 LT in June and July. The percentage deviation between GPS and IRI TEC is also lower than 100\%, except in March at around 04:00 LT, whereas the difference between GPS and IRI TEC is greater than $100 \%$. The percentage deviations in DPS and modeled TEC during dusk periods are always higher than their corre- 
(b)
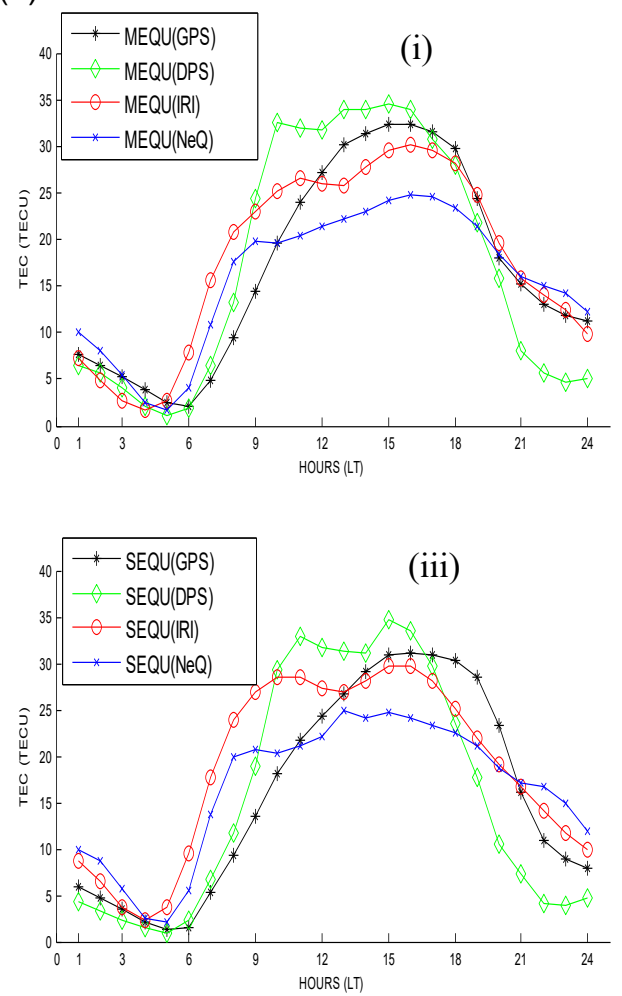
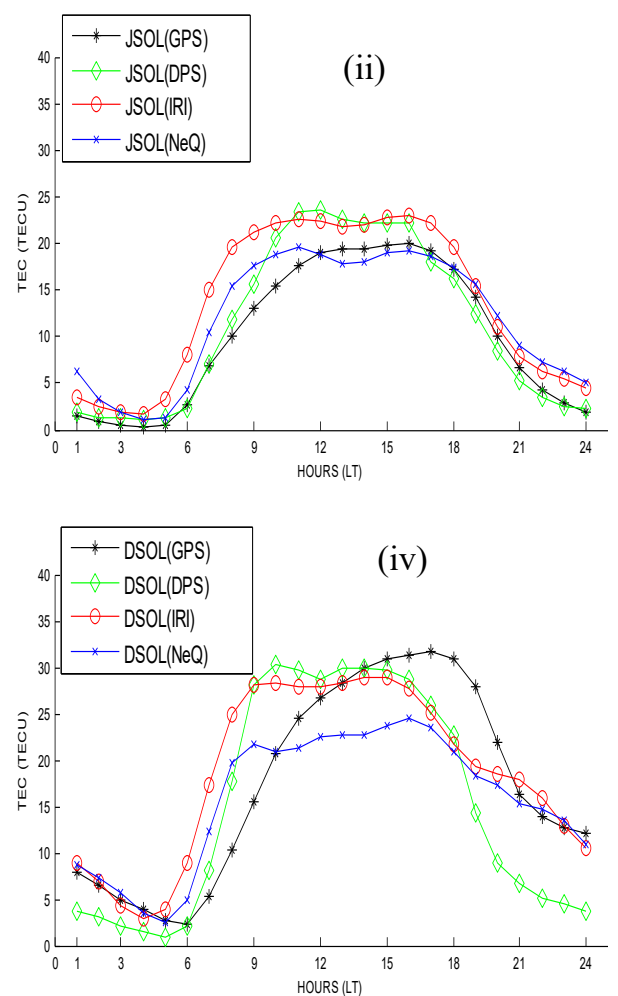

Figure 1. (a) Hourly variations in monthly median of five quiet days of GPS, DPS, IRI, and NeQ TEC in March-December during a quiet period. GPS TEC is denoted by the black line with the star symbol, DPS TEC is denoted by the green line with a diamond symbol, IRI TEC is denoted by the red line with the star symbol and NeQ TEC is denoted by the blue line with the star symbol. (b) Seasonal variations in GPS TEC, DPS TEC, IRI TEC, and NeQ TEC for the (i) March equinox, (ii) June solstice, (iii) September equinox, and (iv) December solstice over Ilorin during quiet periods in 2010. The line colors and symbols are the same as for diurnal variation in Fig. 1a for all seasons.

sponding deviations during the daytime. During the daytime, the deviations are smaller in DPS and NeQ TEC compared to IRI TEC.

\section{Discussion of result}

An investigation into the variations in GPS TEC, DPS TEC, and the validations of modeled TECs in an equatorial region $\left(8.50^{\circ} \mathrm{N}, 4.650^{\circ} \mathrm{E}\right)$ in Africa during low solar activity in the year 2010 has been carried out. The TEC increases gradually from the sunrise period, then slowly reaches the daytime maximum, and later decays to the presunrise minimum. This result indicates that the observed and modeled TEC are a solar zenith angle dependence showing peak and lowest TEC values during noontime and dusk, respectively (Aravindan and Iyer, 1990; Wu et al., 2008 and Kumar and Singh, 2009). Interestingly, our result reveals that the faster rise in the DPS TEC compared to GPS TEC during sunrise is not consistent with the findings of Ezquer et al. (1992) at Tucumán $\left(26.9^{\circ} \mathrm{S} ; 65.4^{\circ} \mathrm{W}\right)$, Belehaki et al. (2004) at Athens, McNamara (1985) at low latitude, and Obrou et al. (2008) at Korhogo $\left(9.33^{\circ} \mathrm{N}, 5.43^{\circ} \mathrm{W}\right.$, Dip $\left.=0.67^{\circ} \mathrm{S}\right)$. They all found that the GPS TEC increased faster than the DPS TEC during the sunrise. The enrichment of PEC on TEC latterly reported by Belehaki et al. (2004) indicated a significant PEC increase in the morning and dusk time. Recently, Jodogne et al. (2004), Mosert et al. (2007), and McKinnell et al. (2007) also obtained a rough estimation of PEC from the GPS and DPS TEC variations. They inferred that the combined GPS TEC and DPS TEC could give the PEC contribution in TEC of a given location. Therefore, the higher rise in DPS TEC compared to GPS TEC during the sunrise in our study could be attributed to inaccurate representation of PEC in the topside DPS TEC profile and incurred error during the extrapolation of the $N_{\mathrm{e}}$ profile from the peak of $\mathrm{F} 2$ region $(\mathrm{NmF} 2)$ to $\sim 1000 \mathrm{~km}$. Therefore, a typical TEC measurement naturally includes a meaningful PEC contribution (Balan and Iyer, 1983; Carlson, 1996; Breed et al., 1997; and Belehaki et al., 2005).

The higher values in DPS TEC compared with IRI TEC around sunrise is not consistent with Rios et al. (2007), who investigated the comparison of DPS TEC and IRI TEC. They found that DPS TEC is smaller than IRI TEC at all hours. They assumed that the prediction of IRI TEC had included 
(a)
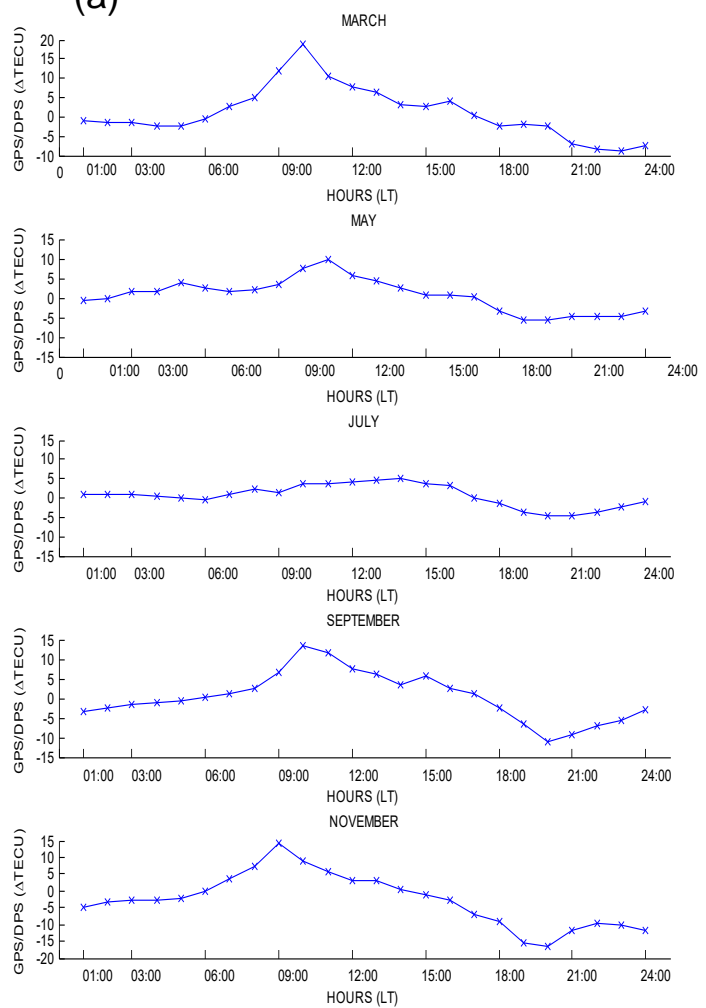

(b)

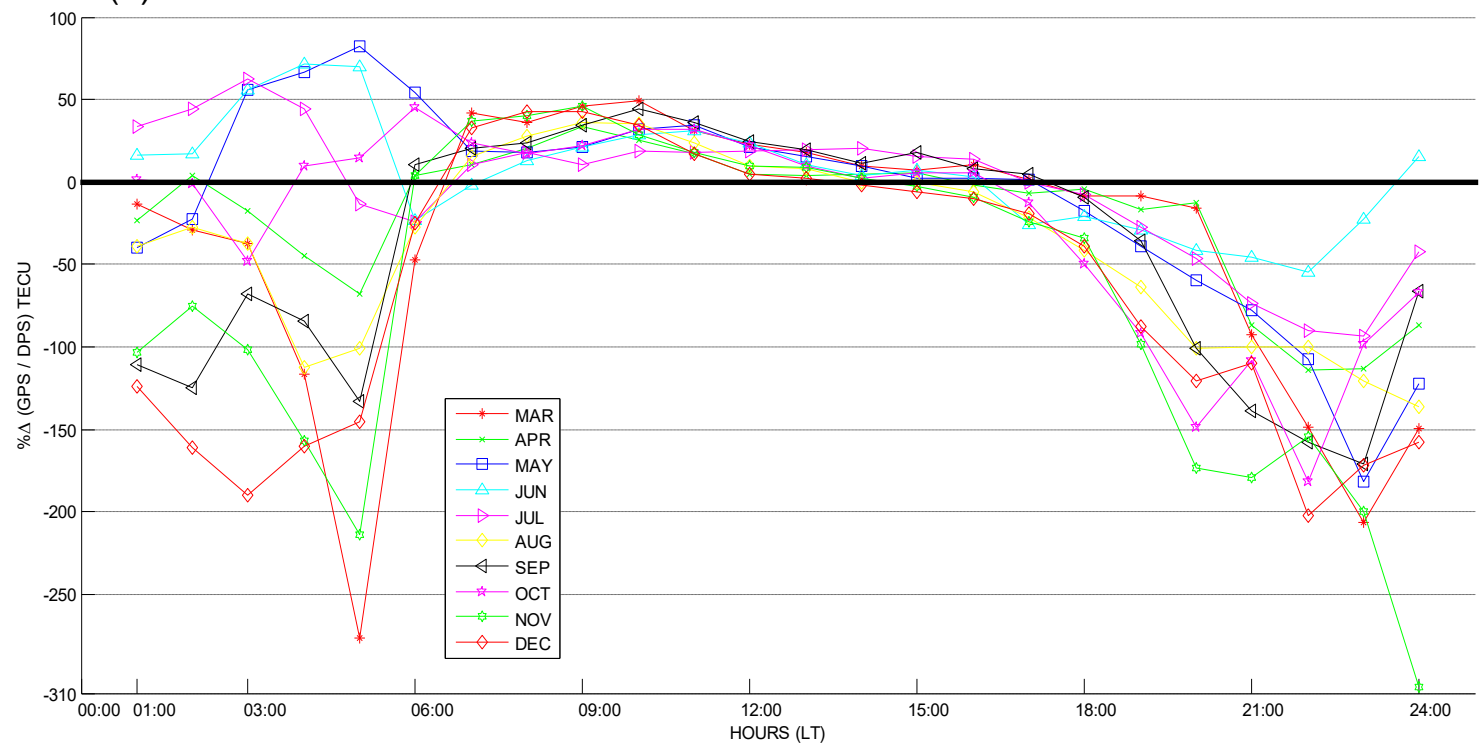

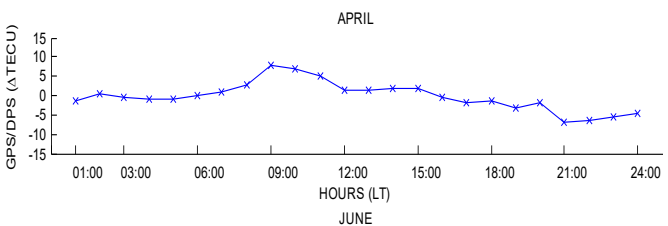
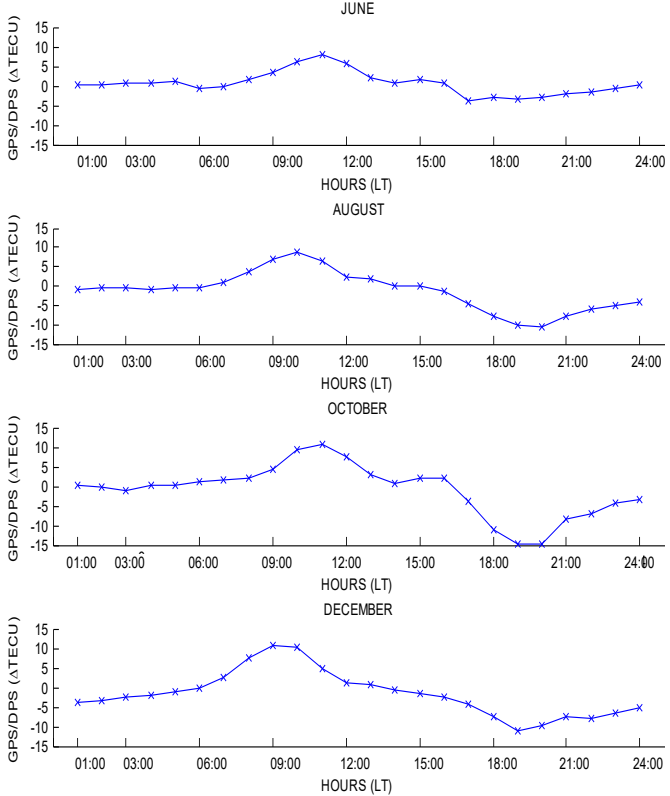

Figure 2. (a) Hourly variations in $\triangle$ TEC between the GPS TEC and DPS TEC from March to December during a quiet period. (b) Mass plot of $\% \triangle$ TEC between the GPS TEC and DPS TEC from March to December during a quiet period. The legend represents line colors and symbols of each deviation in all months.

the high topside $N_{\mathrm{e}}$ profile. Thus, our observation may suggest that the IRI TEC has incorporated low topside $N_{\mathrm{e}}$ profile 
(a)
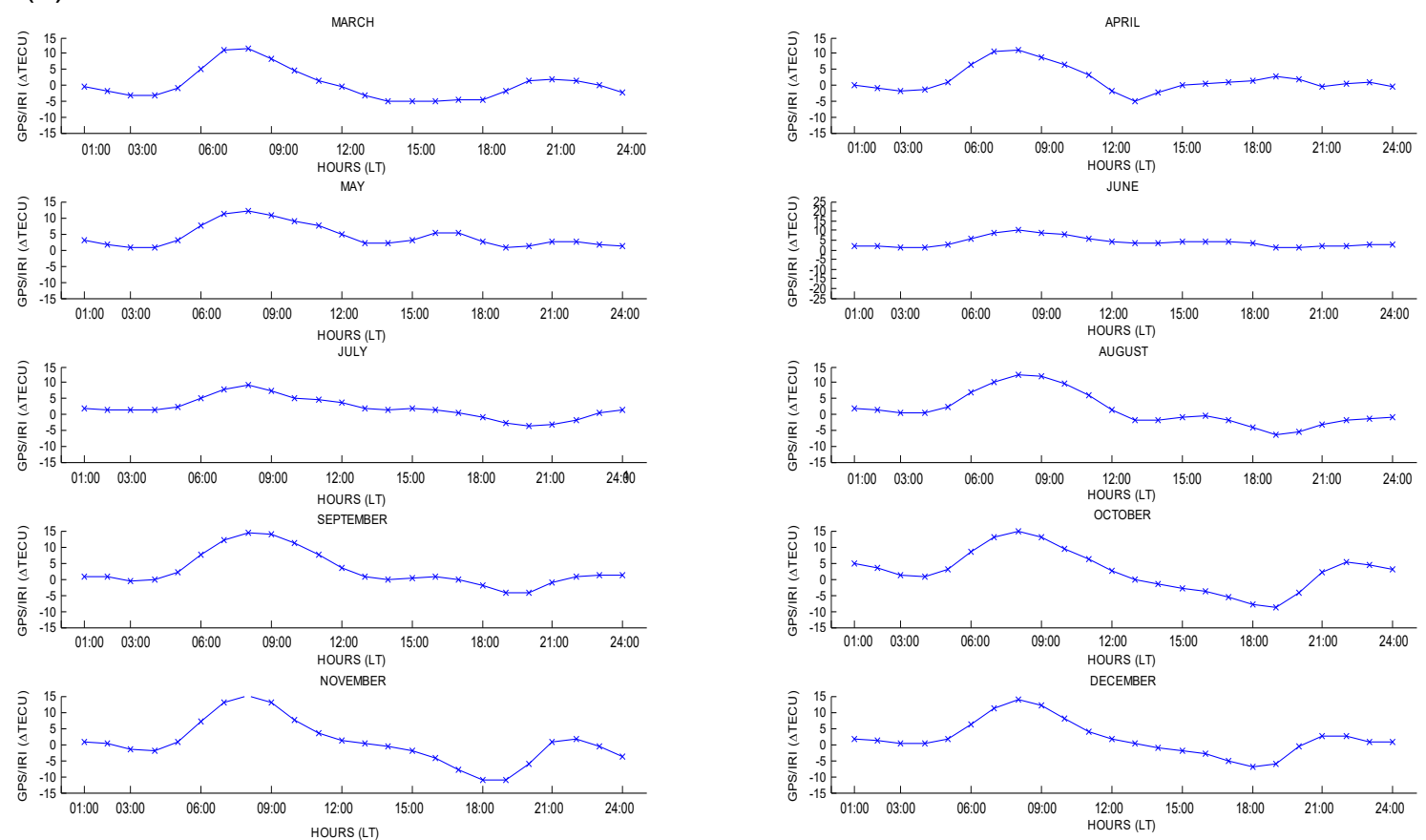

(b)

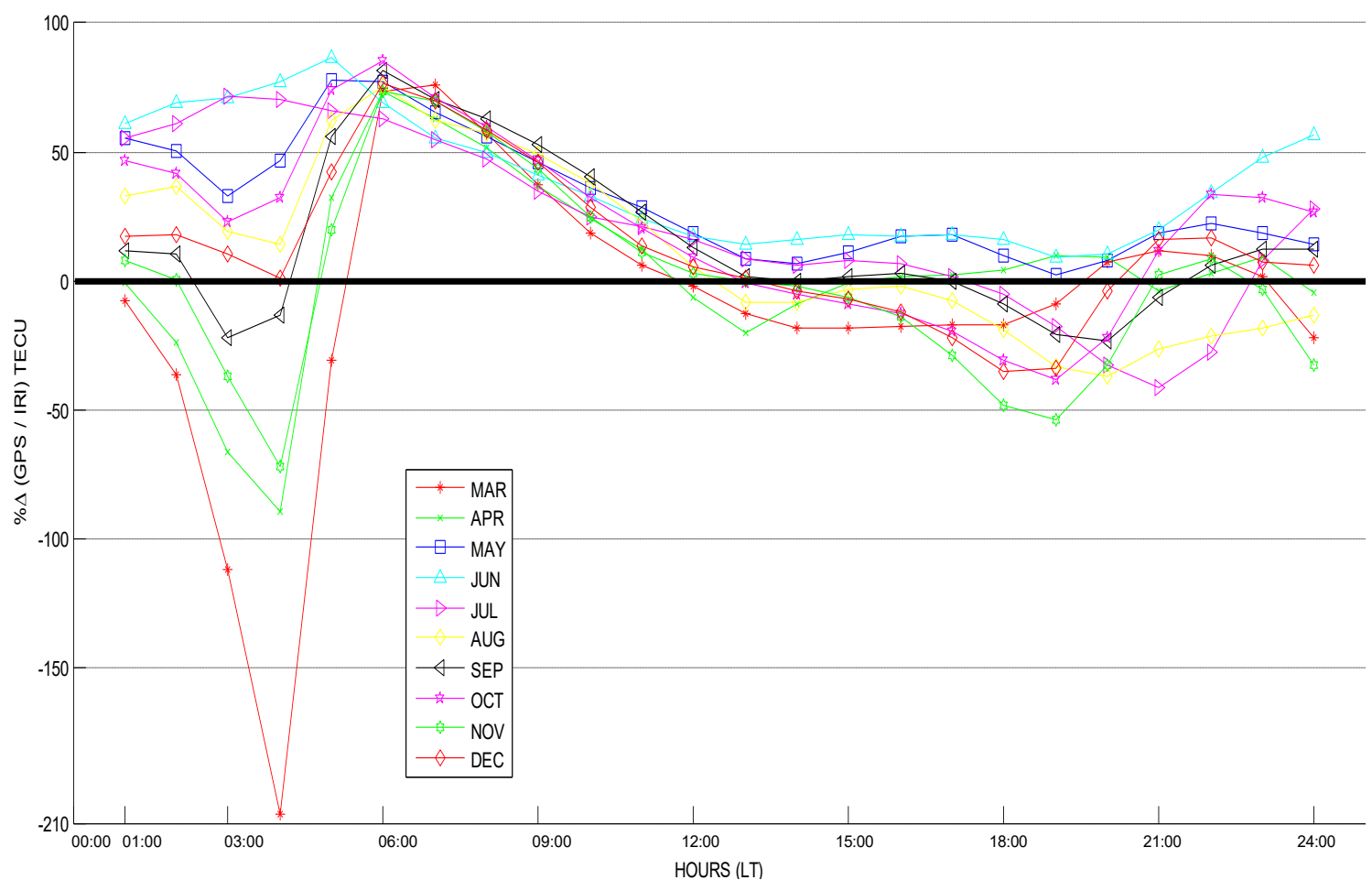

Figure 3. (a) Hourly variations in $\triangle$ TEC between the GPS TEC and IRI TEC from March to December during a quiet period. (b) Mass plot of $\% \Delta$ TEC between the GPS TEC and IRI TEC from March to December during a quiet period. The line colors and symbols are the same as in Fig. 2b. 
(a)
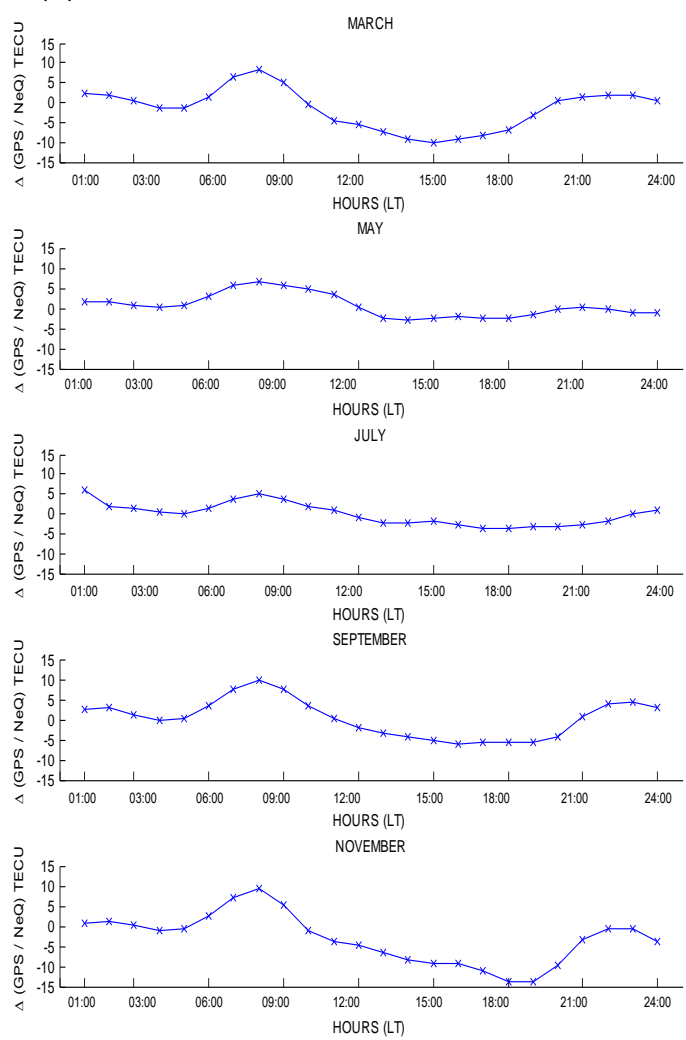
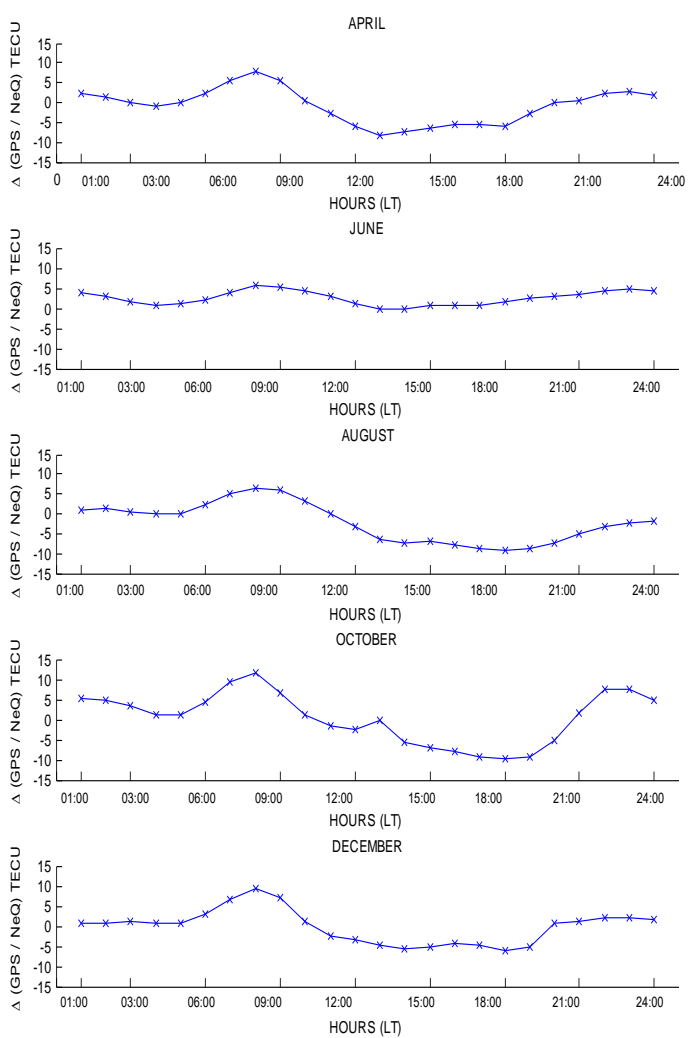

(b)

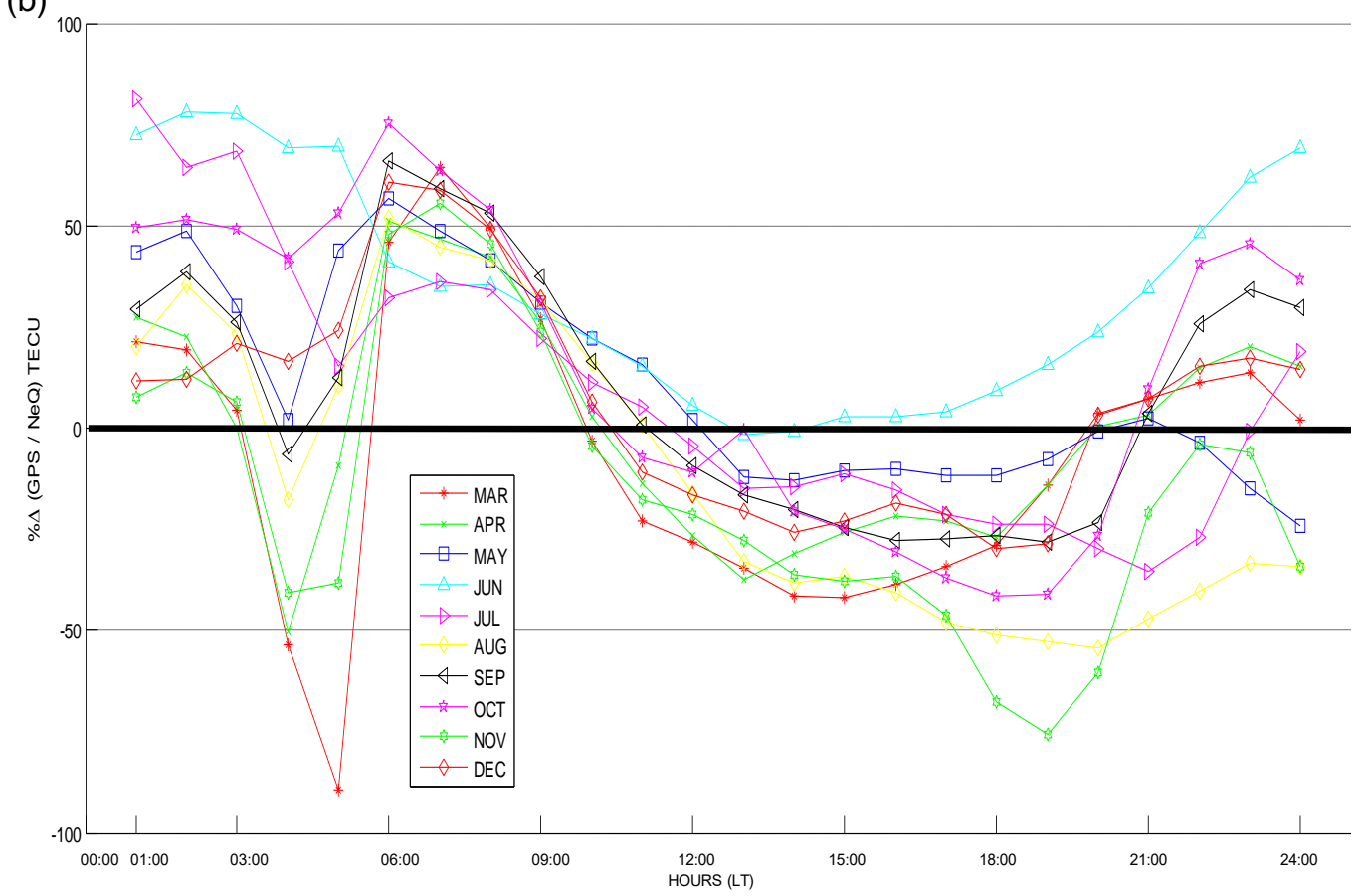

Figure 4. (a) Hourly variations in $\triangle \mathrm{TEC}$ between the GPS TEC and NeQ TEC from March to December during a quiet period. (b) Mass plot of $\% \Delta$ TEC between the GPS TEC and NeQ TEC from March to December during a quiet period. The line colors and symbols are the same as in Fig. 2b. 
The similarity observed during daytime between GPS TEC and DPS TEC in April, August, and December may also suggest that the topside $N_{\mathrm{e}}$ profile in GPS TEC is accurate in the DPS TEC topside profile due to the absence of or negligible PEC contribution in DPS TEC values. The insignificant daytime PEC observed in this study is consistent with Rastogi et al. (1971) and Belehaki et al. (2004). Higher daytime DPS TEC compared with daytime IRI TEC is consistent with the result of McNamara (1985). However, Obrou et al. (2008) found, at the equatorial latitude, higher IRI TEC relative to DPS TEC during low solar activity. Therefore, the reduced daytime IRI TEC compared to GPS TEC values indicates the excessive PEC removal from the model values that its PEC contribution had been raised initially during the sunrise.

Also, the reduced NeQ TEC compared to GPS TEC values in all months is consistent with the reports of Migoya-Orue et al. (2017), Cherniak and Zakharenkova (2016), Rabiu et al. (2014), and Coisson et al. (2009). They recommended an added PEC contribution on the topside NeQ profile for an accurate prediction of the $\mathrm{NeQ}$ model.

The daytime bite-out in TEC is due to the occurrence of the most active fountain effect during noontime at the magnetic equator. The bite-out results from the vertical plasma drift due to the combined consequence of mutually perpendicular electric and magnetic fields on the plasma. The drift lifts the plasma at the magnetic equator and diffuses along geomagnetic field lines into the high latitudes, thereby leaving the reduced TEC at the magnetic equator (Bandyopadhyay, 1970; Skinner, 1966; Bolaji et al., 2012; Olwendo et al., 2013). However, the absence of daytime bite-out (Olatunji, 1967) in GPS TEC in our finding may be due to the greater amount of production at the bottomside and topside electron content that are enhanced quickly to replenish the loss of the ionization that occurs through the fountain effect during noontime.

The percentage difference between observed and modeled TEC reveals that the presunrise values in DPS TEC, IRI TEC, and NeQ TEC require modifications, especially during the month of March for DPS TEC and the models and November and December for DPS TEC only. The daytime DPS TEC is closer to the GPS TEC value compared to the daytime IRI TEC and NeQ TEC values. The nighttime NeQ TEC and IRI TEC perform better with GPS TEC compared with DPS TEC in all months. There is also the need to minimize the discrepancies observed during the dusk periods.

Seasonally, we found that TEC maximizes and minimizes during the equinoxes and the solstices, respectively. Our report is consistent with Bagiya et al. (2009), Wu et al. (2008), Kumar and Singh (2009), and Balan and Rao (1984), who investigated TEC in various regions. They attributed the seasonal variation in TEC to the seasonal differences in thermospheric composition. Moreover, the subsolar point is around the equator during the equinox. Consequently, the sun shines directly over the equatorial latitude, and in addition to the high ratio of $\mathrm{O} / \mathrm{N}_{2}$ around the region, this translates to stronger ionization and generates a semiannual variation in TEC. The finding from our study is consistent with the reports of Skinner (1966), Bolaji et al. (2012), and Scherliess and Fejer (1999), who obtained semiannual variation in TEC. Scherliess and Fejer (1999) also concluded that daytime $\boldsymbol{E} \times \boldsymbol{B}$ drift velocity could result in semiannual variation because the drift is more and less significant in the equinoctial months and June solstice, respectively.

\section{Conclusion}

We have examined the variations in observed and modeled TEC over an equatorial region in Africa during a year of low solar activity. Our findings showed the following:

i. GPS TEC and modeled TEC dependence on solar zenith angle;

ii. a faster sunrise increase in the modeled TEC relative to GPS TEC, which suggests an overestimation of the topside $N_{\mathrm{e}}$ profile of the modeled TEC due to plasmaspheric electron content (PEC) in the models;

iii. a good representation of the daytime measured TEC by the models, suggesting that the model TEC could represent GPS TEC in the absence of plasmaspheric TEC contribution;

iv. that the $\triangle \mathrm{TEC}_{\mathrm{IRI}-\mathrm{GPS}}$ and $\% \Delta \mathrm{TEC}_{\mathrm{IRI}-\mathrm{GPS}}$ in May and June consistently show overestimations at 01:0024:00 LT, indicating the enhanced contribution of PEC at all hours in May and June;

v. that the percentage deviations in DPS and modeled TEC relative to GPS TEC during dusk periods is always higher than their corresponding differences during the daytime, and the values of daytime deviation in DPS and NeQ TEC are smaller compared to daytime deviation in IRI TEC.

This study was carried out during low solar activity in the year 2010; it will be of advantage to investigate and compare similar reviews during high solar activity with our results.

Data availability. The GPS and DPS data are provided by the University of Ilorin, Nigeria, through the archived records of GPS and DPS observatories. The IRI and NeQuick model dataset is available on the websites https://ccmc.gsfc.nasa.gov/modelweb/models/ iri2016_vitmo.php (Community Coordinated Modeling Cente, 2016) and https://tict4d.ictp.it/nequick2/nequick-2-web-mode (Abdus Salam International Centre for theoretical Physics, 2018), respectively. 
Author contributions. OOO carried out the analysis and prepared the paper. JA, OO, OO, IA and EO participated in discussing the results, read the paper, and commented on it.

Competing interests. The authors declare that they have no conflict of interest.

Acknowledgements. The authors thank the US Air Force and Lowell Digisonde, Massachusetts, for the donation and continual maintenance of the DPS. We also appreciate Boston College and the SCINDA group for the donations and continual maintenance of the GPS receiver at the University of Ilorin, Nigeria. We also appreciate the support of the University of Ilorin and CAR-NASRDA for their support in funding of the ionospheric observatories.

Edited by: Ana G. Elias

Reviewed by: Kavutarapu Venkatesh and one anonymous referee

\section{References}

Abdus Salam International Centre for theoretical Physics: the T/ICT4D laboratory, NeQuick 2 web model, https://tict4d.ictp. it/nequick2/nequick-2-web-mode last access: 22 October 2018.

Adewale, A. O., Oyeyemi, E. O., and Olwendo, J.: Solar activity dependence of total electron content derived from GPS observations over Mbarara, Adv. Space. Res., 50, 415-426, 2012.

Akala, A. O., Oyeyemi, E. O., Somoye, E. O., Adeloye, A. B., and Adewale, A. O.: Variability of $f o \mathrm{~F} 2$ in the African equatorial ionosphere, Adv. Space Res., 45, 1311-1314, https://doi.org/10.1016/j.asr.2010.01.003, 2010.

Aravindan, P. and Iyer, K. N.: Day-to-day variability in ionospheric electron content at low latitudes, Planet. Space Sci., 38, 743-750, 1990.

Bagiya, M. S., Joshi, H. P., Iyer, K. N., Aggarwal, M., Ravindran, S., and Pathan, B. M.: TEC variations during low solar activity period (2005-2007) near the Equatorial Ionospheric Anomaly Crest region in India, Ann. Geophys., 27, 1047-1057, https://doi.org/10.5194/angeo-27-1047-2009, 2009.

Balan, N. and Rao, P. B.: Relationship Between Nighttime Total Electron Content Enhancements, J. Geophys. Res., 89, 90099013, 1984.

Balan, N. and Iyer, K. N.: Equatorial anomaly in ionospheric electron content and its relation to dynamo currents, J. Geophys. Res., 88, 10259-10262, 1983.

Bandyopadhyay, P.: Measurement of total electron content at Huancayo, Peru, Planet. Space. Sci., 18, 129-135, https://doi.org/10.1016/0032-0633(70)90150-9, 1970.

Barbas, H. B., Medina, D. C., and Rios, V. H.: Differences between GPS and digisonde measurements of total electron content, Acta Geod. Geophys. Hu., 45, 403-16, 2010.

Belehaki, A., Jakowski, N., and Reinisch, B.W.: Plasmaspheric electron content derived from GPS TEC and digisonde ionograms, Adv. Space Res., 33, 833-837, 2004.

Belehaki, A.: Real-time monitoring for nowcasting and forecasting ionospheric space weather in Europe with ground digisondes, Ann. Geophys., 48, 453-465, 2005.
Bent, R. B., Llewellyn, S. K. and Schmid, P. E.: A highly successful empirical model for the worldwide ionospheric electron density profile, DBA Systems, Melbourne, Florida, USA, 1972.

Bidaine, B. and R. Warnant.: Ionosphere Modelling for Galileo Single Frequency Users: Illustration of the Combination of the NeQuick Model and GNSS Data Ingestion, Adv. Space Res., 47, 312-322, doi.org/10.1016/j.asr.2010.09.001, 2011.

Bilitza, D.: International reference ionosphere.: Recent developments, Radio Sci., 21, 343-346, 1986.

Bilitza, D.: International Reference Ionosphere 2000, Radio Sci., 36, 261-275, 2000.

Bilitza, D. and Rawer, K.: International Reference Ionosphere Model, Adv. Space Res., 69, 520-829, 1998.

Bolaji, O. S., Adeniyi, J. O., Radicella, S. M., and Doherty, P. H.: Variability of total electron content over an equatorial West African station during low solar activity, Radio Sci., 47, 1-9, https://doi.org/10.1029/2011RS004812, 2012.

Breed, A. M., Goodwin, G. L., Vandenberg, A. M., Essex, E. A., Lynn, K. J. W., and Silby, J. H.: Ionospheric total electron content and slab thickness determined in Australia, Radio Sci., 32, 1635$1643,1997$.

Carlson, H. C.: Incoherent scatter radar mapping of polar electrodynamics, J. Atmos.Sol.-Terr. Phy., 58, 37-56, 1996.

Cherniak, I. and Zakharenkova, I.: NeQuick and IRI-Plas model performance on topside electron content representation: Spaceborne GPS measurements, Radio Sci., 51, 752-766, 2016.

Coisson, P., Radicella, S. M., Leitinger, R., and Nava, B.: Topside electron density in IRI and NeQuick: features and limitations, Adv. Space Res., 37, 937-942, 2006.

Coisson, P., Nava, B., and Radicella, S. M.: On the use of NeQuick topside option in IRI-2007, Adv. Space Res., 43, 1688-1693, 2009.

Community Coordinated Modeling Center (CCMC): International Reference Ionosphere - IRI, available at: https://ccmc.gsfc.nasa. gov/modelweb/models/iri2016_vitmo.php (last access: 22 October 2018), 2016.

de Jesus, R., Fagundes, P. R., Coster, A., Bolaji, O. S., Sobral, J. H. A., Batista, I. S., de Abreu, A. J., Venkatesh, K., Gende, M., Abalde, J. R., and Sumod, S. G.: Effects of the intense geomagnetic storm of September-October 2012 on the equatorial, low-and mid-latitude F region in the American and African sector during the unusual 24th solar cycle strength, J. Atmos. Terr. Phys., 138, 93-105, 2016.

Ezquer, R. G., Adler, N. O., Radicella, S. M., Gonzalez, M. M., and Manza, J. R.: Total electron content obtained from ionogram data alone, Radio Sci., 27, 429-434, 1992.

Huang, X. and Reinisch, B. W.: Vertical electron density profiles from the digisonde network, Adv. Space Res., 18, 121-129, 1996a.

Huang, X. and Reinisch, B. W.: Vertical electron density profiles from digisonde ionograms. The average representative profile, Ann. Geophys., 39, 751-756, 1996b.

Huang, X. and Reinisch, B. W.: Vertical electron content from ionograms in real time, Radio Sci., 36, 335-342, 2001.

Jee, G., Schunk, R. W., and Scherliess, L.: On the sensitivity of total electron content (TEC) to upper atmospheric/ionospheric parameters strength, J. Atmos. Terr. Phys., 67, 1040-1052, 2005. 
Jodogne, J.-C., Nebdi, H., and Warnan, R.: Advances in Radio Science GPS TEC and ITEC from Digisonde Data Compared with NeQuick Model, Adv. Radio Sci., 2, 269-273, 2004.

Karia, S. P. and Pathak, K. N.: GPS based TEC measurement for a period Aug 2008-Dec 2009 near the northern crest of India equatorial ionospheric anomaly region, J. Earth Syst. Sci., 120, 851-858, 2011.

Kenpankho, P., Supnithi, P., and Nagatsuma, T.: Comparison of observed TEC values with IRI-2007 TEC and IRI-2007 TEC with optional foF2 measurements predictions at an equatorial region, Chumphon, Thailand, Adv. Space Res., 52, 1820-1826, 2013.

Kumar, S. and Singh, A. K.: Variation of ionospheric total electron content in Indian low latitude region of the equatorial anomaly during May 2007-April 2008, Adv. Space Res., 43, 1555-1562, 2009.

Langley, R., Fedrizzi, M., Paula, E., Santos, M., and Komjathy, A.: Mapping the low latitude ionosphere with GPS, GPS World, 13, 41-46, 2002.

Leong, S. K., Musa, T. A., Omar, K., Subari, M. D., Pathy, N. B., and Asillam, M. F.: Assessment of ionosphere models at Banting: Performance of IRI-2007, IRI-2012 and NeQuick 2 models during the ascending phase of Solar Cycle 24, Adv. Space Res., 55, 1928-1940, 2015.

Liu, J. Y., Tsai, H. F., and Jung, T. K.: Total electron content obtained by using the global positioning system, Terr. Atmos. Oceanic Sci., 7, 107-117, 1996.

Mannucci, A. J., Wilson, B. D., and Edwards, C. D.: A new method for monitoring the Earth's ionospheric total electron content using the GPS global network, paper presented at ION GPS-93, Inst. of Navigation., 1323-1332, 1993.

McKinnell, L. A., Opperman, B., and Cilliers, P. J.: GPS TEC and ionosonde TEC over Grahamstown, South Africa: First comparisons, Adv. Space Res., 39, 816-820, 2007.

McNamara, L. F.: The use of total electron content measurements to validate empirical models of the ionosphere, Adv. Space Res., 5, 81-90, 1985.

Migoya Orué, Y. O., Radicella, S. M., Coïsson, P., Ezquer, R. G., and Nava, B.: Comparing TOPEX TEC Measurements with IRI Predictions, Adv. Space Res., 42, 757-762, 2008.

Migoya-Orué, Y., Folarin-Olufunmilayo, O., Radicella, S., AlazoCuartas, K., and Rabiu, A. B.: Evaluation of NeQuick as a model to characterize the Equatorial Ionization Anomaly over Africa using data ingestion, Adv. Space Res., 60, 1732-1738, 2017.

Mosert, M., Gende, M., Brunini, C., Ezquer, R., and Altadill, D.: Comparisons of IRI TEC predictions with GPS and digisonde measurements at the Ebro, Adv. Space Res., 39, 841-847, 2007.

Obrou, O. K., Mene, M. N., Kobea, A. T., and Zaka, K. Z.: Equatorial total electron content (TEC) at low and high solar activity, Adv. Space Res., 43, 1757-1761, 2008.

Okoh, D., McKinnell, L. A., Cilliers, P., Okere, B., Okonkwo, C., and Rabiu, B.: IRI-vTEC versus GPS-vTEC for Nigerian SCINDA GPS stations, Adv. Space Res., 55, 1941-1947, 2015.

Olatunji, E. O.: The total columnar electron content of the equatorial ionosphere strength, J. Atmos. Terr. Phys., 29, 277-285, 1967.

Olawepo, A. O., Oladipo, O. A, Adeniyi, J. O., and Doherty, P. H.: TEC response at two equatorial stations in the African sector to geomagnetic storms, Adv. Space Res., 56, 19-27, 2015.

Olwendo, O. J., Baki, P., Cilliers, P. J., Mito, C., and Doherty, P.: Comparison of GPS TEC Measurements with IRI-2007
TEC Prediction over the Kenyan Region during the Descending Phase of Solar Cycle 23, Adv. Space Res., 49, 914-921, https://doi.org/10.1016/j.asr.2011.12.007, 2012.

Olwendo, O. J., Baki, P., Cilliers, P. J., Mito, C., and Doherty, P.: Comparison of GPS TEC Variations with IRI-2007 TEC Prediction at Equatorial Latitudes during a Low Solar Activity (20092011) Phase over the Kenyan Region, Adv. Space Res., 52, 1770-1779, 2013.

Rabiu, A. B., Adewale, A. O., Abdulrahim, R. B., and Oyeyemi, E. O.: Science Direct TEC Derived from Some GPS Stations in Nigeria and Comparison with the IRI and NeQuick Models, Adv. Space Res., 53, 1290-1303, https://doi.org/10.1016/j.asr.2014.02.009, 2014.

Radicella, S. M., Bilitza, D., Reinisch, B. W., and Adeniyi, J. O., Mosert Gonzalez, M. E., Zolesi, B., Zhang, M. L., and Zhang, S.: IRI Task Force Activity At ICTP: Proposed Improvements For The IRI Region Below The F Peak, Adv. Space Res., 22, 731-739, 1998.

Rama Rao, P. V. S., Niranjan, K., Prasad, D. S. V. V. D., Gopi Krishna, S., and Uma, G.: On the validity of the ionospheric pierce point (IPP) altitude of $350 \mathrm{~km}$ in the Indian equatorial and low-latitude sector, Ann. Geophys., 24, 2159-2168, https://doi.org/10.5194/angeo-24-2159-2006, 2006a.

Rastogi, R. G. and Sharma, R. P.: Ionospheric electron content at Ahmedabad (near the crest of the equatorial anomaly) by using beacon satellite transmissions during half a solar cycle, Planet. Space Sci., 19, 1505-1517, 1971.

Rastogi, R. G., Iyer, K. N., and Bhattacharyya, J. C.: Total electron content of the ionosphere over the magnetic equator, Current Sci., 531-533, 1975.

Reinisch, B. W. and Huang, X.: Deducing topside profiles and total electron content from bottomside ionograms, Adv. Space Res., 27, 23-30, 2001.

Reinisch, B. W., Huang, X., Belehaki, A., and Ilma R.: Using Scale Heights Derived from Bottomside Ionograms for Modelling the IRI Topside Profile, Adv. Radio Sci., 2, 293-297, 2004.

Reinisch, B. W., Huang, X., Galkin, I. A., Paznukhov, V., and Kozlov, A.: Recent advances in the real-time analysis of ionograms and ionospheric drift measurements with digisondes strength, J. Atmos. Terr. Phys., 67, 1054-1062, 2005.

Rios, V. H., Medina, C. F., and Alvarez, P.: Comparison between IRI predictions and digisonde measurements at Tucuman Strength, J. Atmos. Terr. Phys., 69, 569-577, 2007.

Scherliess, L. and Fejer, B.: Radar and satellite global equatorial F region vertical drift model, J. Geophys. Res., 104, 6829-6842, 1999.

Skinner, N. J.: Measurements of Total Electron Content Near The Magnetic Equator, Planet. Space Sci., 14, 1123-1129, 1966.

Sulungu, E. D., Uiso, C. B., and Sibanda, P.: Comparison of GPS derived TEC with the TEC predicted by IRI 2012 model in the southern Equatorial Ionization Anomaly crest within the Eastern Africa region, Adv. Space Res., 61, 1660-1671, 2018.

Tariku, Y. A.: Patterns of GPS-TEC variation over low-latitude regions (African sector) during the deep solar minimum (2008 to 2009) and solar maximum (2012 to 2013) phases, Earth Planets Space, 67, 1-9, 2015.

Wu, C.-C., Liou, K., Shan, S. J., and Tseng, C. L.: Variation of ionospheric total electron content in Taiwan region of the equato- 
rial anomaly from 1994 to 2003, Adv. Space Res., 41, 611-616, 2008.

Yu, X., She, C., Liu, D., and Zhen, W.: October. A preliminary study of the NeQuick model over China using GPS TEC and ionosonde data. In Antennas, Propagation \& EM Theory (ISAPE), 2012 10th International Symposium on IEEE, Xian, China, 627-630, 22-26 October 2012.
Zhang, M. L., Shi, J. K., Wang, X., and Radicella, S. M.: Ionospheric variability at low latitude station: Hainan, China, Adv. Space Res., 34, 1860-1868, 2004.

Zhang, M. L., Radicella, S. M., Shi, J. K., Wang, X., and Wu, S. Z.: Comparison among IRI, GPS-IGS and ionogram-derived total electron contents, Adv. Space Res., 37, 972-977, 2006. 